\title{
Characterization of Fluorophores Released from Three Kinds of Lake Phytoplankton Using Gel Chromatography and Fluorescence Spectrophotometry
}

\author{
Shinichi AokI,* Shinya OHARa,* Keiichiro KImura,* Hirotaka MizuguchI,** Yasuro Fuse,** \\ and Etsu YAMADA $*, * * \dagger$ \\ *Department of Chemistry and Material Technology, Kyoto Institute of Technology, \\ Matsugasaki, Sakyo, Kyoto 606-8585, Japan \\ **Center for Environmental Science, Kyoto Institute of Technology, Matsugasaki, Sakyo, Kyoto 606-8585, Japan
}

\begin{abstract}
Three kinds of phytoplankton were cultivated, and the contribution of dissolved organic matter (DOM) released from the phytoplankton was examined to clarify the cause of organic pollution of Lake Biwa. Microcystis aeruginosa, Staurastrum dorcidentiferum, and Cryptomonas ovata were evaluated with regard to cultivation. A significant peak $\left(M_{\mathrm{w}}:<3000 \mathrm{Da}\right)$ was mainly detected in the algal DOM released from plankton during cultivation by gel chromatography with a fluorescence detector $\left(E_{\mathrm{x}}=340 \mathrm{~nm}, E_{\mathrm{m}}=435 \mathrm{~nm}\right)$. Since this peak corresponds to a peak with lower molecular weight in three peaks detected in the surface water of Lake Biwa, it can be concluded that the algal DOM released from the plankton during cultivation makes a considerable contribution to the refractory organic matter in Lake Biwa. Three fluorescence maxima were observed in the cultivation of three kinds of phytoplankton: two fulvic-like fluorescence peaks (A and B) and a protein-like fluorescence peak (C). These peaks became larger as their cell counts of plankton increased. As for the fractionations of algal DOM using DAX-8, the ratio of hydrophilic DOM is fairly high in DOM produced by three kinds of phytoplankton. The order of the amount of algal DOM per cell volume during cultivation was Cryptomonas ovata > Microcystis aeruginosa $>$ Staurastrum dorcidentiferum. These results suggest that the increase of the refractory organic matter in Lake Biwa may be attributed to a change of the predominant phytoplankton.
\end{abstract}

(Received May 29, 2008; Accepted September 1, 2008; Published November 10, 2008)

\section{Introduction}

In Lake Biwa, the largest lake in Japan, an annual increase of chemical oxygen demand (COD) has been observed since 1985 , although the values of biochemical oxygen demand (BOD) and chlorophyll- $a$ have remained almost constant. Moreover, the values of COD in the rivers that flow into Lake Biwa have not increased. ${ }^{1}$ These results suggest that refractory organic matter may have accumulated in Lake Biwa.

In several lakes, chemical fractionation methods have been applied to analyze the temporal changes of DOC. ${ }^{2}$ Imai et al. divided the DOC occurring in Lake Biwa into six fractions, and reported that the hydrophilic acid fraction contained more than $40 \%$ of the total DOC, whereas the hydrophobic acid fraction contained less than $30 \%{ }^{3}$ Hori et al. found that the fraction with adsorptivity to hydrous iron oxide consisted primarily of refractory organic carbon. ${ }^{4-6}$ In a previous study, we reported that the main origin of hydrophobic acids in Lake Biwa may be humic substances from soils around the rivers that flow into Lake Biwa, while hydrophilic acids may be due to inner production by phytoplankton. ${ }^{7,8}$

However, few studies about the contribution of the inner production by phytoplankton to DOM have been carried out. Therefore, the optical and fluorescence characteristics of algal

† To whom correspondence should be addressed.

E-mail: eyamada@kit.ac.jp
DOM from Microcystis aeruginosa were examined. ${ }^{9}$ Since 1985, when the increase in COD began,${ }^{1}$ the predominant kind of phytoplankton has changed from green algae to dark-brown whip-hair algae, and it is possible that the change in the production of organic substances due to the change in the kind of plankton affects the increase in COD (Fig. S1 (Supporting Information)). ${ }^{10}$ Measurements indicating that phytoplankton has become the predominant species in Lake Biwa are being carried out twice monthly.

In the present research, the kinds of phytoplankton that were predominant before and after 1985 in Lake Biwa were cultivated, and the algal-derived DOM and fluorophores released from phytoplankton during cultivation were determined for a comparison with the results from Microcystis aeruginosa. Staurastrum dorcidentiferum of green algae and Cryptomonas ovata of dark-brown whip-hair algae were selected as the predominant algal species before and after 1985, respectively. The effects of the algal-derived DOM on the refractory DOM in Lake Biwa and their characteristics were investigated using gel chromatography with a fluorescence detector and a threedimensional excitation-emission matrix (3-DEEM) technique.

\section{Experimental}

\section{Reagents and materials}

Three kinds of phytoplankton, Microcystis aeruginosa (NIES-109, Lake Yogo, Shiga), Staurastrum dorcidentiferum 
(NIES-665, Lake Biwa, Shiga), and Cryptomonas ovata (NIES275, Tsuchiura, Ibaraki), which were supplied by the National Institute for Environmental Studies, were used. Staurastrum dorcidentiferum of green algae and Cryptomonas ovata of darkbrown whip-hair algae were selected as the predominant algal species before and after 1985 , respectively. ${ }^{11}$

Humic acid (HA; Aldrich Chemicals) was purified by repeated dissolution in $0.1 \mathrm{M}$ sodium hydroxide and precipitation in 0.1 $\mathrm{M}$ hydrochloric acid until the color of the supernatant solution was eliminated. ${ }^{12}$ Fulvic acids (FA) obtained from A-horizons of brown forest soil (Dystric Cambisol, Dando, Aichi, Japan) and ando soil (Humic Andozol, Inogashira, Shizuoka, Japan) were used. ${ }^{13,14}$ Fulvic acids prepared according to methods developed by the International Humic Substances Society (IHSS) were supplied by the Japan Humic Substances Society and used as a standard without purification. All other chemicals were of the best commercial grade available. Pure water was prepared using a Millipore Milli-Q water purification system.

\section{Cultivation of phytoplankton}

Three kinds of phytoplankton were cultivated in the media. Three incubators (an Iwaki LIB-302, an Iwaki ICB-142L, and an NIK LH-100SP) were used for the cultivation of plankton. A TOMY BS-305 autoclave was used for sterilization. Microcystis aeruginosa was grown in 1-L triangular bottles at $20^{\circ} \mathrm{C}$ and 2000 lux under a $12 \mathrm{h:12}$ h light/dark cycle in an MA medium ${ }^{9}$ and an improved VT medium (Table S1). Staurastrum dorcidentiferum was grown in 1-L triangular bottles at $20^{\circ} \mathrm{C}$ and 2000 lux under a $12 \mathrm{~h}: 12 \mathrm{~h}$ light/dark cycle in an AF-6 medium (Table S2) and an improved VT medium. Cryptomonas ovata was grown in 1-L triangular bottles at $15^{\circ} \mathrm{C}$ and 2000 lux under a $12 \mathrm{~h}: 12 \mathrm{~h}$ light/dark cycle in a VT medium (Table S1) and an improved VT medium. The improved VT medium was used to examine DOM produced by lake phytoplankton for a comparison in the same kind of medium. The concentration of glycylglycine in an improved VT medium was prepared to be one-tenth of that in a VT medium because culture media with lower DOC were necessary. Cell counts were followed using a microscope every week for 78 days in an improved VT medium and for 98 days in other media, respectively. An Olympus IX71N-22PH-D microscope and a KEYENCE VHX-100F digital microscope were used to count the algae.

\section{Procedure for the determination of algal-derived DOM}

For the determination of algal-derived DOM, the samples filtered through a Millipore membrane filter $(0.45 \mu \mathrm{m})$ were used. The cells of the phytoplankton were quantitatively separated from the medium by filtration. Changes in the time of DOC and specific ultraviolet absorbance at $260 \mathrm{~nm}\left(\mathrm{SUVA}_{260}\right)$ were noted in cultivation experiments. Two TOC meters, a Shimadzu TOC-5000A and a Shimadzu TOC-V CSH, were used for the determination of DOC. A JASCO V-530 spectrophotometer was used to measure the UV-absorbance (260 $\mathrm{nm}$ ) of water samples. The specific ultraviolet absorbance (SUVA) is defined as the UV absorbance of a water sample at a given wavelength normalized for the DOC concentration. SUVA $_{260}$ was indicated to be strongly correlated with aromatic compounds. ${ }^{9,15,16}$ A Horiba F-51 pH meter and a TOA CM-60S EC meter were used to measure the $\mathrm{pH}$ and electric conductivity in environmental water samples, respectively. For measuring the BOD, a Tech-jam B-100Z BOD meter was used.

Dissolved organic substances were analyzed using ge chromatography with a fluorescence detector, which was developed for simultaneous determinations of the concentration and molecular weight of humic substances. ${ }^{17}$ The apparatus used for HPLC was a Shimadzu LC-10AD chromatography pump equipped with a Shimadzu RF-535 fluorescence detector. The excitation wavelength $\left(E_{\mathrm{x}}\right)$ was $340 \mathrm{~nm}$, and the emission wavelength $\left(E_{\mathrm{m}}\right)$ was $435 \mathrm{~nm}$. A Shimadzu C-R7A chromatopac was used for data analysis. Test samples were applied to a gel filtration column (Superose12 HR10/30 $(300 \times 10 \mathrm{~mm}$ i.d., Pharmacia Biotech)) using a sample injector (Rheodyne 7125) with a $100-\mu 1$ loop. A $0.01 \mathrm{M}$ sodium hydroxide solution was used as an eluent at a flow rate of $0.4 \mathrm{ml} \mathrm{min}^{-1}$. Here, the column void volume $\left(V_{\mathrm{o}}\right)$ (elution volume for Blue Dextran 2000) was $7.38 \mathrm{ml}$, and the total bed volume $\left(V_{\mathrm{t}}\right)$ was $23.6 \mathrm{ml}$. A Pharmacia Biotech low-molecular-weight gel filtration calibration kit and vitamin $\mathrm{B}_{12}$ were used for determining the molecular weights of these peaks. ${ }^{17}$

Fractionation of DOM produced by three kinds of phytoplankton was carried out according to a method of Nagai et al. ${ }^{8}$ The hydrophobic and hydrophilic fractions of DOM were isolated using Supelco DAX-8 resin (equivalent XAD-8 resin). Filtered samples were acidified to $\mathrm{pH} 2$ with $\mathrm{HCl}$ and passed through a DAX-8 resin column $(50 \mathrm{~mm} \times 10 \mathrm{~mm}$ i.d. $)$ to adsorb hydrophobic fractions of DOM. Furthermore, hydrophobic acids were eluted from the resin with $0.1 \mathrm{M} \mathrm{NaOH}$.

According to a method of Nagao et al. ${ }^{18}$ the fluorescence properties were measured with 3-DEEM using a fluorescence spectrophotometer, a Shimadzu RF-5300PC, creating highresolution fluorescence running with band-pass width slits of $5 \mathrm{~nm}$ for both excitation and emission. The excitation and emission wavelengths were scanned from 220 to $500 \mathrm{~nm}$ and from 250 to $600 \mathrm{~nm}$ at a scan speed of $1500 \mathrm{~nm} / \mathrm{min}$, respectively. The fluorescence readings were normalized by the fluorescence intensity $\left(E_{\mathrm{x}}=345 \mathrm{~nm}, E_{\mathrm{m}}=450 \mathrm{~nm}\right)$ of $10 \mu \mathrm{g} / 1$ quinine sulfate $\left(0.05 \mathrm{M} \mathrm{H}_{2} \mathrm{SO}_{4}\right.$ solution) $10 \mathrm{QSU}$. The values were treated as the relative fluorescence intensity (RFI).

Ultrafilter membranes (Millipore ultrafree-C centrifugal filter, available at 3000, 5000, and 30000 molecular weights) were used to fractionate the algal DOM by a centrifuge (Millipore Tibitan). The fractions of algal DOM were measured by 3 DEEM.

\section{Results and Discussion}

Time changes in the cell counts and DOC during the cultivation of three kinds of phytoplankton

Three kinds of phytoplankton were cultivated not only in their recommended media, but also in an improved VT medium. The improved VT medium was used for comparing the algal DOM released from phytoplankton during cultivation in the same kind of medium. The time changes in the cell counts of three kinds of phytoplankton during cultivation are shown in Fig. 1(a). The cell count of Microcystis aeruginosa in an MA medium increased until day 36 of incubation, when it reached a maximum of $1.7 \times 10^{7}$ cells $/ \mathrm{ml}$, and was almost constant after that until day 49 of incubation, when it reached the stationary phase. It decreased after that due to cell death. The time change in the growth curve of Microcystis aeruginosa in an improved VT medium was similar to that in an MA medium, and the cell count reached a maximum of $1.1 \times 10^{7}$ cells $/ \mathrm{ml}$, which was almost the same as the cell count in an MA medium. On the other hand, Staurastrum dorcidentiferum in an AF-6 medium was in the proliferation period until day 77 of incubation. The cell count of Staurastrum dorcidentiferum was $3.1 \times 10^{4}$ cells $/ \mathrm{ml}$. The growth curve of Staurastrum dorcidentiferumin in an improved VT medium was similar to that in an AF-6 medium. The cell count of Cryptomonas ovata in an improved VT 

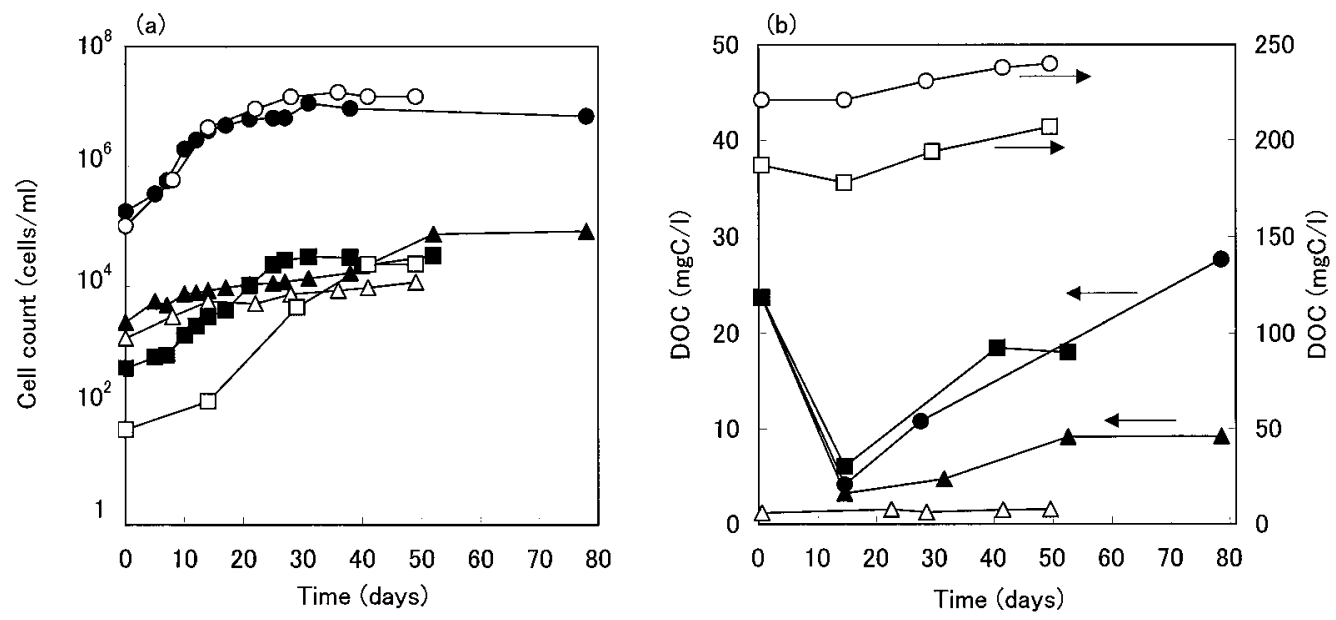

Fig. 1 Time changes in the cell counts (a) and DOC (b) of three plankton during cultivation in a MA medium (O), in an AF-6 medium $(\triangle)$, in a VT medium ( $\square$ ) and in an improved VT medium $(\bullet$, $\boldsymbol{\Lambda}, \boldsymbol{\square})$. O, $\bullet$, Microcystis aeruginosa; $\triangle, \mathbf{\Lambda}$, Staurastrum dorcidentiferum; $\square, \mathbf{\square}$, Cryptomonas ovata.
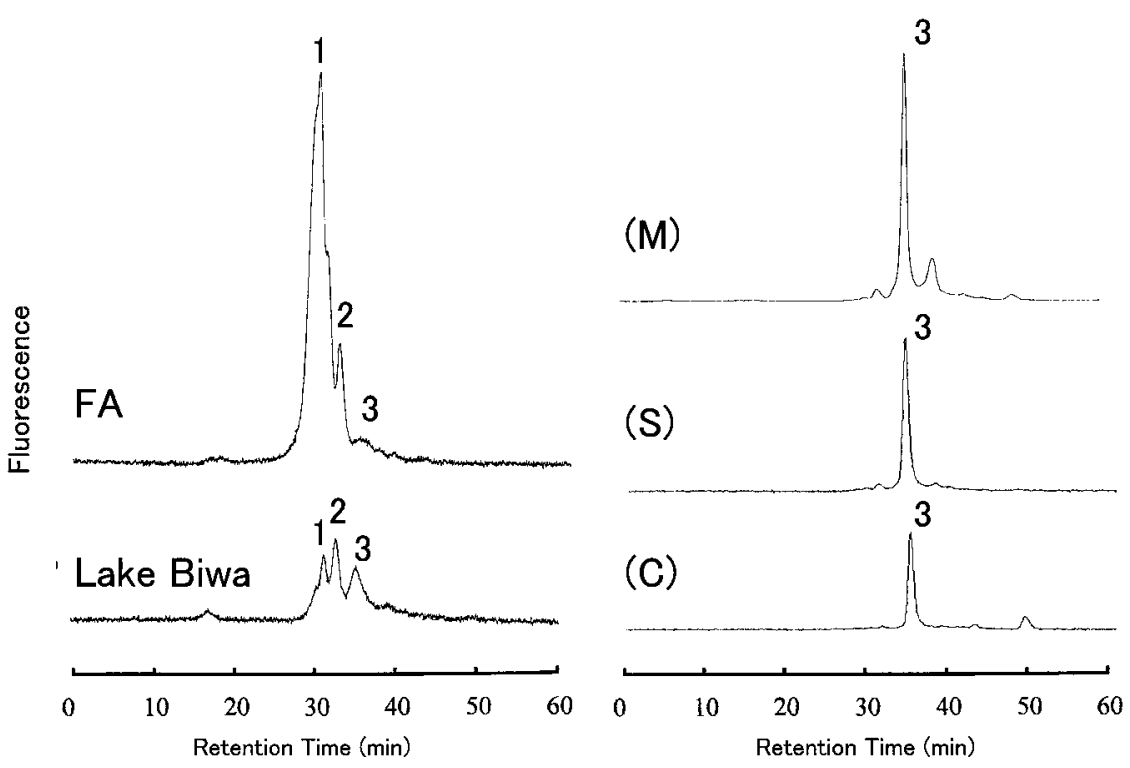

Fig. 2 Gel chromatograms of fulvic acid (FA), surface water sample of Lake Biwa (Biwako-ohashi May 8, 2006), and algal-derived DOM produced by Microcystis aeruginosa (M), Staurastrum dorcidentiferum (S), and Cryptomonas ovata (C) during cultivation in an improved VT medium. FA, Lake Biwa, attenuation $=2$; algal DOM, attenuation $=4$.

medium increased until day 31 of incubation, when it reached $3.1 \times 10^{4}$ cells $/ \mathrm{ml}$. The growth curve of Cryptomonas ovata in a VT medium was slightly smaller than that in an improved VT medium.

Time changes in the values of DOC caused by the cultivation of Microcystis aeruginosa, Staurastrum dorcidentiferum, and Cryptomonas ovata are shown in Fig. 1(b). The MA medium and the VT medium were not adequate to examine DOM produced by phytoplankton because the DOC values of both media are very high. The improved VT medium was adequate to investigate DOM produced by plankton, because the DOC concentration is relatively low. After day 14 of incubation, the DOC concentrations decreased by $82.5,86.4$, and $74.4 \%$ due to respiration for Microcystis aeruginosa, Staurastrum dorcidentiferum, and Cryptomonas ovata, respectively, and increased after that due to the production of DOM by phytoplankton. The increase in the DOC concentrations of
DOM produced by Microcystis aeruginosa and Cryptomonas ovata was larger than that by Staurastrum dorcidentiferum.

Fluorescence properties of algal DOM by gel chromatography and 3-DEEM

Gel chromatograms of the standard FA of soil origin (Inogashira), a surface water sample of Lake Biwa (Biwakoohashi, May 8, 2006), and algal-derived DOM released from three kinds of plankton are shown in Fig. 2. In the case of the surface water of Lake Biwa, three peaks $(\mathrm{RT}=30,32$, and 35 min) were detected, which are similar to those of the standard FA. ${ }^{9,17}$ However, the ratio of peak 1 was lower than that of soil FA. The molecular weights of peaks 1 and 2 were estimated to be $5000-10000$ and $3000-5000 \mathrm{Da}$, respectively. ${ }^{17}$ These peaks detected in Lake Biwa were almost constant after 98 days, and the results confirmed the likely existence of refractory organic matter. ${ }^{9}$ In the gel chromatograms of Microcystis 
aeruginosa during cultivation in a MA medium for 28 days (Fig. 2(M)), peak $2(\mathrm{RT}=32 \mathrm{~min})$ and peak $3(\mathrm{RT}=35 \mathrm{~min})$ were detected, and peak 3 was particularly large. The gel chromatograms of Microcystis aeruginosa during cultivation in an improved VT medium were similar to those during cultivation in a MA medium. These results suggest that organic substances with the same fluorescent characteristics and a lower molecular weight of FA may be formed during the cultivation of Microcystis aeruginosa. The gel chromatograms of Staurastrum dorcidentiferum and Cryptomonas ovata during cultivation in an improved VT medium for 14 days are shown in Figs. 2(S) and 2(C), respectively. In the gel chromatograms of Staurastrum dorcidentiferum and Cryptomonas ovata, peak 3 ( $\mathrm{RT}=35 \mathrm{~min}$ ) was particularly large. The molecular weight of peak 3 was estimated to be lower than $3000 \mathrm{Da}$.

For a fluorescence measurement of DOM by 3-DEEM, filtered water samples were accurately measured without further treatment. Two fluorescence maxima were observed in the soil FA sample (Fig. 3(a)): one at $E_{\mathrm{x}} / E_{\mathrm{m}}$ values of $320 / 440 \mathrm{~nm}$ (peak $\mathrm{A})$, and the other at $E_{\mathrm{x}} / E_{\mathrm{m}}$ values of $240-250 / 430-440 \mathrm{~nm}$ (peak B). ${ }^{9}$ The fluorescence peak positions for extracted FA from rivers, lakes, and soils reported in previous studies were 240 - 250/440 - $445 \mathrm{~nm}$ and $300-395 / 406-490 \mathrm{~nm},{ }^{19-23}$ and those for HA from soils were $305-365 / 425-490 \mathrm{~nm}$ and $440-455 / 510-550 \mathrm{~nm} .{ }^{24-26}$ These are the so-called fulvic-like fluorescence peaks. In the surface water of Lake Biwa, two fulvic-like peaks and another peak with $E_{\mathrm{x}} / E_{\mathrm{m}}$ values of 280/330 nm (peak C) were observed (Fig. 3(b)). ${ }^{9}$ A predominance of FA in the DOM of Lake Biwa and the rivers has been reported. ${ }^{12,17}$ The results of 3-DEEM also indicate that the fulvic-like component dominates humic-like substances in Lake Biwa. The observed peak $\mathrm{C}$ is similar to the fluorescence of protein material reported in previous studies, and is often referred to as protein-like fluorescence. ${ }^{20,27-30}$

Since the $\mathrm{pH}$ and metal ions in the culture media may have effects on the fluorescence properties of algal DOM, the effects were investigated. When the samples were adjusted to $\mathrm{pH} 7-8$, changes in the fluorescence intensities and the $E_{\mathrm{x}} / E_{\mathrm{m}}$ values of soil FA and algal DOM by the addition of culture medium were hardly observed. Then, all filtered algal samples were adjusted to $\mathrm{pH} 7-8$ before fluorescence measurements of DOM by 3 DEEM. Peaks A, B, and $\mathrm{C}$ and another peak with $E_{\mathrm{x}} / E_{\mathrm{m}}$ values of 240/370 nm were observed in the algal DOM from Microcystis aeruginosa during cultivation in both the MA medium (Fig. 3(c)) and the improved VT medium (Fig. 3(d)). The values of the RFI of the peaks with $E_{\mathrm{x}} / E_{\mathrm{m}}$ values of $240 / 370$ $\mathrm{nm}$ were the largest of those of the observed peaks in both media. The 3-DEEM contour plots of algal-derived DOM for Staurastrum dorcidentiferum and Cryptomonas ovata during cultivation in an improved VT medium are shown in Figs. 3(e) and 3(f), respectively. Two fulvic-like fluorescence peaks (A and $\mathrm{B}$ ) and a protein-like fluorescence peak $(\mathrm{C})$ were detected, and these peaks became larger as their cell counts of plankton increased. However, the fluorescence peaks of Staurastrum dorcidentiferum were smaller than those of Microcystis aeruginosa and Cryptomonas ovata.

Time variations in the fluorescent intensities of the algal DOM released from three kinds of plankton were measured by gel chromatography with a fluorescence detector $\left(E_{\mathrm{x}}=340 \mathrm{~nm}, E_{\mathrm{m}}\right.$ $=435 \mathrm{~nm}$ ) and 3-DEEM. Since the fluorescent intensity of peak $3(\mathrm{RT}=35 \mathrm{~min})$ became the highest of those of the peaks detected for the three kinds of phytoplankton, the time variations in the fluorescent intensity of peak $3(\mathrm{RT}=35 \mathrm{~min})$ at the exponential phase are shown in Fig. 4(a). The fluorescent intensity (peak 3) of the algal DOM from Microcystis
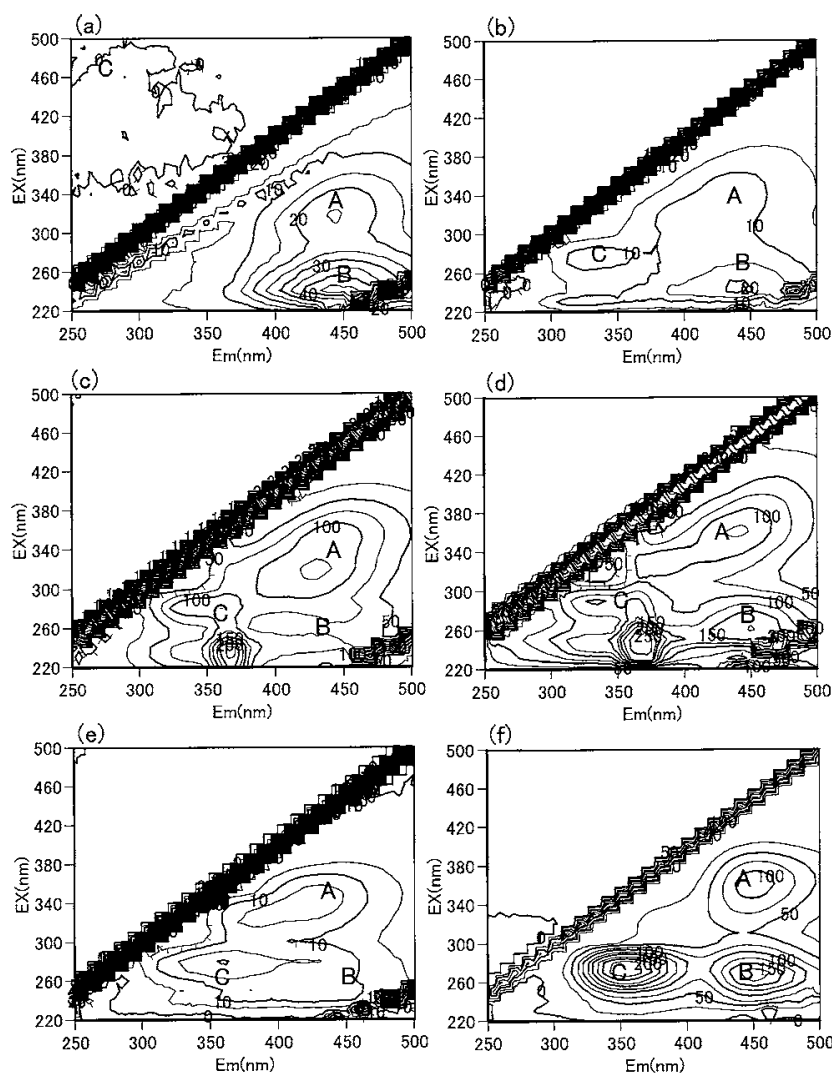

Fig. 3 3-DEEM contour plots of soil FA, surface water of Lake Biwa, and algal-derived DOM for three plankton. (a) Soil FA (Dando, $4 \mathrm{mg} / \mathrm{l}$ ), (b) surface water of Lake Biwa collected at Biwakoohashi March 11, 2006, (c) algal-derived DOM for Microcystis aeruginosa during cultivation for 36 days in an MA medium and (d) for 27 days in an improved VT medium, (e) algal-derived DOM for Staurastrum dorcidentiferum during cultivation for 31 days in an improved VT medium, (f) algal-derived DOM for Cryptomonas ovata during cultivation for 40 days in an improved VT medium.

aeruginosa during cultivation in an improved VT medium increased slowly until the 14th day, and abruptly increased after that. On the other hand, the fluorescent intensity of the products during the cultivation of Staurastrum dorcidentiferum in an improved VT medium increased gradually. Cryptomonas ovata showed a similar tendency to Staurastrum dorcidentiferum. The time variations in the fluorescent intensities of peaks A, B, and $\mathrm{C}$ of algal DOM for three kinds of plankton measured by 3DEEM are shown in Fig. 4(b). The RFI values of peaks A, B, and C of DOM produced by Microcystis aeruginosa and Cryptomonas ovata increased gradually. The values of the RFI of peaks B and C in Microcystis aeruginosa and Cryptomonas ovata at the stationary phase were larger than those of peak A. However, the RFI values of peaks A, B, and C in Staurastrum dorcidentiferum were low compared with those in Microcystis aeruginosa and Cryptomonas ovata.

\section{Fractionation of algal DOM from three kinds of phytoplankton}

The fractionation of algal DOM produced by three kinds of phytoplankton during cultivation in an improved VT medium was carried out using DAX-8 resin. ${ }^{8}$ Standard fulvic acids of soil origin (Inogashira and Dando) were quantitatively adsorbed on the DAX-8, and estimated to be hydrophobic DOM. The results are listed in Table 1. The ratios of hydrophilic DOM, hydrophobic acid, and hydrophobic neutral in the primary 

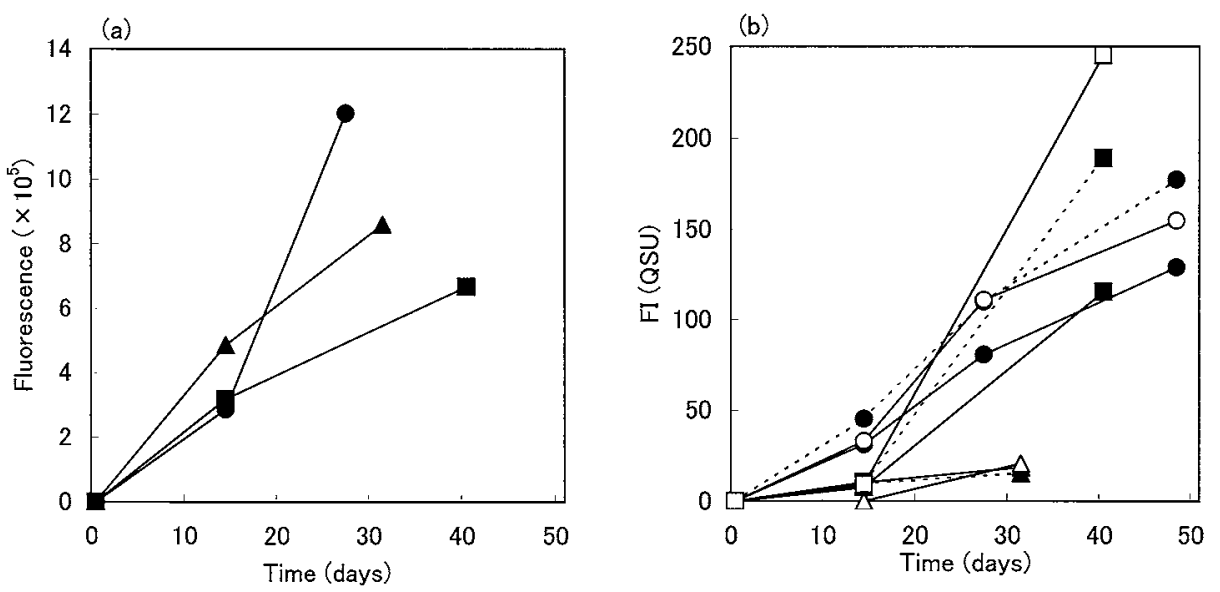

Fig. 4 Time variations in the fluorescent intensity ( $R T=35 \mathrm{~min}$ ) (a) and fluorescence intensities of

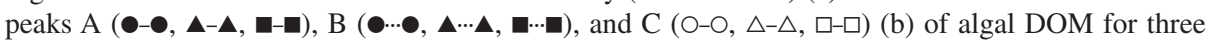
kinds of phytoplankton during cultivation in an improved VT medium. $\bullet, \bigcirc$, Microcystis aeruginosa; $\Delta, \triangle$, Staurastrum dorcidentiferum; $\mathbf{\square}, \square$, Cryptomonas ovata.

Table 1 Fractionation of algal-derived dissolved organic matter (DOM) released from three kinds of phytoplankton during cultivation in an improved VT medium

\begin{tabular}{lccccc}
\hline \multirow{2}{*}{ Phytoplankton } & \multirow{3}{*}{ Cultivation } & \multicolumn{4}{c}{$\mathrm{DOC} / \mathrm{mg} \mathrm{Cl}^{-1}$} \\
\cline { 3 - 6 } & & $\mathrm{Hi}$ & $\mathrm{HoA}$ & $\mathrm{HoN}$ & Total \\
\hline \multirow{2}{*}{ Microcystis } & \multirow{2}{*}{27 days } & 6.67 & 3.00 & 1.16 & 10.83 \\
& & $(61.6)$ & $(27.7)$ & $(10.7)$ & $(100.0)$ \\
& \multirow{2}{*}{48 days } & 7.75 & 3.18 & 1.00 & 11.93 \\
& & $(65.0)$ & $(26.6)$ & $(8.4)$ & $(100.0)$ \\
Staurastrum & \multirow{2}{*}{31 days } & 3.86 & 0.76 & 0.12 & 4.74 \\
& & $(81.4)$ & $(16.0)$ & $(2.6)$ & $(100.0)$ \\
Cryptomonas & \multirow{2}{*}{40 days } & 15.79 & 1.57 & 1.09 & 18.45 \\
& & $(85.6)$ & $(8.5)$ & $(5.9)$ & $(100.0)$ \\
\hline
\end{tabular}

Hi, hydrophilic DOM; HoA, hydrophobic acid; HoN, hydrophobic neutral.

The values in parentheses are the ratios $(\%)$

product from Microcystis aeruginosa after incubation for 27 days were $61.6,27.7$, and $10.7 \%$, respectively, which were almost identical to the ratios after incubation for 48 days. In the case of Staurastrum dorcidentiferum after incubation for 31 days, the ratios of hydrophilic DOM, hydrophobic acid, and hydrophobic neutral were $81.4,16.0$, and $2.6 \%$, respectively. The ratios of hydrophilic DOM, hydrophobic acid, and hydrophobic neutral in the algal DOM from Cryptomonas ovata after incubation for 40 days were 85.6, 8.5, and 5.9\%, respectively. The specific ultraviolet absorbance, SUVA 260 (E260/DOC), for the cultivation of Microcystis aeruginosa, Staurastrum dorcidentiferum, and Cryptomonas ovata was 16.0, 5.91 , and $6.65 \mathrm{~cm}^{-1}(\mathrm{gC})^{-1} 1$, respectively. The values of $\mathrm{SUVA}_{260}$ for pedogenic DOC and autochthonous DOC were reported to be $23-58$ and $8-16 \mathrm{~cm}^{-1}(\mathrm{gC})^{-1} 1$, respectively. ${ }^{31,32}$ Then, algal DOM from three kinds of phytoplankton may be attributed to autochthonous DOC because the $\mathrm{SUVA}_{260}$ values were low. These results suggest that the ratio of hydrophilic DOM is fairly high in DOM produced by three kinds of phytoplankton and the ratio of hydrophobic DOM in the algal DOM from Microcystis aeruginosa is two-times higher than those from Staurastrum dorcidentiferum and Cryptomonas ovata.

The 3-DEEM contour plots of the hydrophilic DOM and
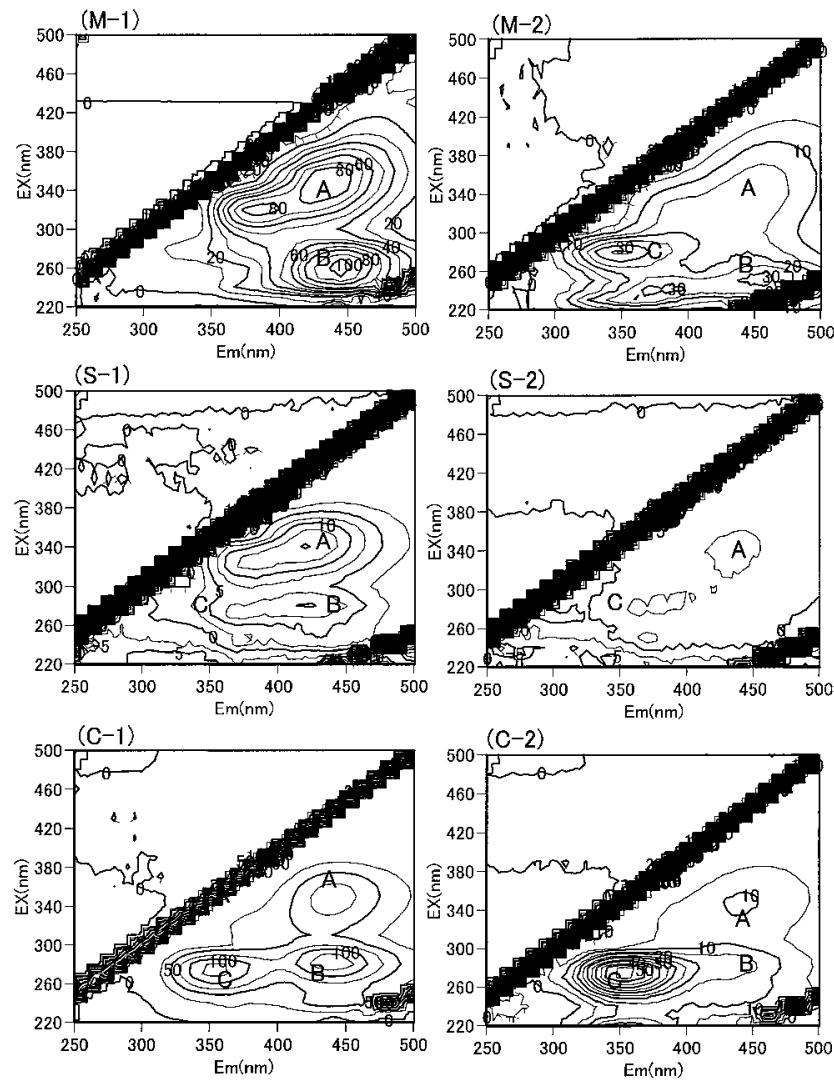

Fig. 5 3-DEEM contour plots of the hydrophilic fractions (M-1, S-1, C-1) and hydrophobic fractions (M-2, S-2, C-2) of the algalderived DOM for three plankton during cultivation in an improved VT medium. (M-1, M-2) Microcystis aeruginosa, (S-1, S-2) Staurastrum dorcidentiferum, (C-1, C-2) Cryptomonas ovata.

hydrophobic acid fractions of algal DOM from three kinds of phytoplankton are shown in Fig. 5. The results are listed in Table 2. Peaks A and B, which are fulvic-like fluorescence peaks, were detected in the hydrophilic fractions of algal DOM for Microcystis aeruginosa. Peaks A, B, and C in the hydrophobic fractions were observed, but the fluorescence intensity of peak C (36.1 QSU) was the largest among all three 
Table 2 Fractionation of fluorophores released from three kinds of phytoplankton during cultivation in an improved VT medium

\begin{tabular}{|c|c|c|c|c|c|c|c|c|c|c|}
\hline & & & & $\mathrm{Hi}$ & & & $\mathrm{oA}$ & & & otal \\
\hline Phytoplan & xton & & RFI/ & RFI/DOC/ & & RFI/ & RFI/DOC/ & $E_{\mathrm{x}} / E_{\mathrm{m}} /$ & RFI/ & RFI/DOC/ \\
\hline Microcystis & Peak A & $340 / 430$ & 89.3 & 11.5 & $330 / 440$ & 19.7 & 6.20 & $360 / 440$ & 129.0 & 10.8 \\
\hline & Peak B & $260 / 445$ & 105.7 & 13.6 & $250 / 455$ & 32.4 & 10.2 & $260 / 450$ & 177.4 & 14.9 \\
\hline & Peak C & $290 / 335$ & 10.2 & 1.32 & $280 / 350$ & 36.1 & 11.4 & $290 / 335$ & 154.8 & 13.0 \\
\hline & & $320 / 385$ & 86.7 & 11.2 & $330 / 385$ & 10.9 & 3.43 & $330 / 385$ & 114.9 & 9.63 \\
\hline Staurastrum & Peak A & $340 / 420$ & 15.2 & 3.93 & $340 / 435$ & 2.8 & 3.7 & $340 / 425$ & 18.5 & 3.94 \\
\hline & Peak B & $280 / 425$ & 10.4 & 2.69 & $290 / 430$ & 2.4 & 3.17 & $280 / 430$ & 15.3 & 3.26 \\
\hline & Peak C & $270 / 375$ & 8.8 & 2.28 & $290 / 365$ & 3.0 & 3.96 & $280 / 360$ & 20.5 & 4.36 \\
\hline Cryptomonas & Peak A & $350 / 440$ & 88.8 & 5.62 & $350 / 440$ & 10.7 & 6.80 & $360 / 450$ & 115.3 & 6.25 \\
\hline & Peak B & $280 / 440$ & 144.9 & 9.18 & $290 / 450$ & 16.2 & 10.3 & $270 / 450$ & 189.1 & 10.3 \\
\hline & Peak C & $270 / 355$ & 131.9 & 8.35 & $270 / 350$ & 56.5 & 35.9 & $270 / 355$ & 245.3 & 13.3 \\
\hline
\end{tabular}

Incubation of 48 days, 31 days and 40 days for Microcystis, Staurastrum and Cryptomonas, respectively.

Table 3 DOC, relative fluorescence intensities (RFI) and E260 of the algal DOM per cell volume for the phytoplankton during cultivation

\begin{tabular}{|c|c|c|c|c|c|c|}
\hline \multirow{3}{*}{ Phytoplankton } & \multirow{3}{*}{ Medium } & \multicolumn{5}{|c|}{ Value per the cell volume } \\
\hline & & \multirow{2}{*}{$\mathrm{DOC} / \mathrm{mg} \mathrm{C}\left(\mu \mathrm{m}^{3}\right)^{-1}$} & \multicolumn{3}{|c|}{$\mathrm{RFI} / \mathrm{QSU}\left(\mu \mathrm{m}^{3}\right)^{-1} \mathrm{~L}^{-1}$} & \multirow{2}{*}{$\mathrm{E} 260 /\left(\mathrm{cm} \cdot \mu \mathrm{m}^{3}\right)^{-1}$} \\
\hline & & & Peak A & Peak B & Peak C & \\
\hline \multirow[t]{2}{*}{ Microcystis } & $A(36 d)$ & $9.9 \times 10^{-12}$ & $1.2 \times 10^{-10}$ & $7.1 \times 10^{-11}$ & $1.1 \times 10^{-10}$ & $4.7 \times 10^{-10}$ \\
\hline & $\mathrm{B}(27 \mathrm{~d})$ & $2.6 \times 10^{-11}$ & $3.1 \times 10^{-10}$ & $4.3 \times 10^{-10}$ & $3.8 \times 10^{-10}$ & - \\
\hline Staurastrum & $B(31 d)$ & $1.1 \times 10^{-11}$ & $4.3 \times 10^{-11}$ & $3.5 \times 10^{-11}$ & $4.7 \times 10^{-11}$ & $1.6 \times 10^{-11}$ \\
\hline Cryptomonas & $B(40 d)$ & $4.9 \times 10^{-10}$ & $3.1 \times 10^{-9}$ & $5.0 \times 10^{-9}$ & $6.5 \times 10^{-9}$ & $2.7 \times 10^{-9}$ \\
\hline
\end{tabular}

A, MA medium; B, improved VT medium. Cell volume: Microcystis, $65 \mu \mathrm{m}^{3}$; Staurastrum, $32000 \mu \mathrm{m}^{3}$; Cryptomonas, $1700 \mu \mathrm{m}^{3}$.

peaks, and the intensities of peaks A and B (19.7 and 32.4 QSU) in the hydrophobic DOM were about 3 - 5 times lower than those in the hydrophilic DOM (89.3 and 105.7 QSU). It seems that the fulvic-like fluorescence of hydrophilic DOM may be large compared with that of hydrophobic DOM, and protein-like fluorescence DOM may be mainly hydrophobic acid and hydrophobic neutral in the algal DOM from Microcystis aeruginosa. In the hydrophilic and hydrophobic fractions of algal DOM for Cryptomonas ovata, peaks A, B, and C were observed; the intensities of peaks A and B (88.8 and 144.9 QSU) in the hydrophilic DOM were about 8 - 9 times higher than those (10.7 and 16.2 QSU) in the hydrophobic DOM, and the fluorescence intensity of peak C (131.9 QSU) in the hydrophilic DOM was 2.3-times higher than that (56.5 QSU) in the hydrophobic DOM, respectively. Both the fulvic-like fluorescence and protein-like fluorescence of hydrophilic DOM may be large compared with those of hydrophobic DOM in the algal DOM for Cryptomonas ovata. The molecular weights of protein-like fluorescence DOM (peak C) for Microcystis aeruginosa were estimated to be over $30000 \mathrm{Da}$ using an ultra filter membrane, consistent with the results using gel chromatography. On the other hand, the molecular weights of protein-like fluorescence DOM (peak C) for Cryptomonas ovata were estimated to be less than 30000 Da using both methods. In the hydrophilic and hydrophobic fractions of algal DOM for Staurastrum dorcidentiferum, peaks A, B, and C were observed, and the intensities of these peaks were low compared with those for Cryptomonas ovata, but the ratios of the hydrophilic and hydrophobic fractions were similar to those for Cryptomonas ovata. The results indicate that algal DOM from Microcystis aeruginosa has similar fluorescence to that from Staurastrum dorcidentiferum and Cryptomonas ovata, but exhibits somewhat hydrophobic characteristics compared with those from the other two plankton.

Comparison of the values of DOC, RFI and E260 per cell volume for the phytoplankton during cultivation

In order to compare the DOM produced by three kinds of plankton during cultivation, the values of DOC, RFI and E260 per cell volume were calculated, and are listed in Table 3. The cell volume for Microcystis aeruginosa, Staurastrum dorcidentiferum, and Cryptomonas ovata was reported to be 65 , 32000 , and $1700 \mu \mathrm{m}^{3}$, respectively. ${ }^{33,34}$ The DOC values per cell volume during the cultivation of Microcystis aeruginosa, Staurastrum dorcidentiferum, and Cryptomonas ovata in an improved VT medium were $2.6 \times 10^{-11}, 1.1 \times 10^{-11}$, and $4.0 \times$ $10^{-10} \mathrm{mgC}\left(\mu \mathrm{m}^{3}\right)^{-1}$, respectively. The E260 values per cell volume during the cultivation of Microcystis aeruginosa, Staurastrum dorcidentiferum, and Cryptomonas ovata were 4.7 $\times 10^{-10}, 1.6 \times 10^{-11}$, and $2.7 \times 10^{-9}\left(\mathrm{~cm} \cdot \mu \mathrm{m}^{3}\right)^{-1}$, respectively. The DOC values per cell volume during cultivation increased in the following order: Staurastrum dorcidentiferum < Microcystis aeruginosa $<$ Cryptomonas ovata. The order of the three kinds of plankton for E260 was similar to that for DOC. The RFI values of peaks A, B, and C per cell volume for Microcystis aeruginosa during cultivation in an improved VT medium were $3.1 \times 10^{-10}, 4.3 \times 10^{-10}$, and $3.8 \times 10^{-10}$ QSU $\left(\mu \mathrm{m}^{3}\right)^{-1} \mathrm{l}^{-1}$, respectively, which were similar to those during cultivation in a MA medium. The RFI values of peaks A, B, and C per cell volume for Staurastrum dorcidentiferum during cultivation in an improved VT medium were $4.3 \times 10^{-11}, 3.5 \times 10^{-11}$, and $4.7 \times$ $10^{-10} \mathrm{QSU}\left(\mu \mathrm{m}^{3}\right)^{-1} 1^{-1}$, respectively. The RFI values of peaks A, 
B, and C per cell volume for Cryptomonas ovata during cultivation in an improved VT medium were $3.1 \times 10^{-9}, 5.0 \times$ $10^{-9}$, and $6.5 \times 10^{-9} \mathrm{QSU}\left(\mu \mathrm{m}^{3}\right)^{-1} 1^{-1}$, respectively. The order of the three kinds of plankton for the RFI values of peaks A, B, and C per cell volume was similar to their order for DOC and E260. The results indicate that the order of the amount of algal DOM during cultivation was Cryptomonas ovata > Microcystis aeruginosa $>$ Staurastrum dorcidentiferum.

\section{Acknowledgements}

We would like to express our sincere appreciation to Dr Naoyuki Kishimoto of Ryukoku University and Prof. Hajime Karatani of Kyoto Institute of Technology for their kind suggestions with regard to the cultivation of phytoplankton. The present study was supported by a Grant-in-Aid for Scientific Research from the Ministry of Education, Science, and Culture (No. 17310008).

\section{Supporting Information}

Composition of improved VT medium and VT medium is listed in Table S1. The composition of AF-6 medium is listed in Table S2. Annual changes in the predominant algal species and COD in Lake Biwa are shown in Fig. S1. This material is available free of charge on the web at http://www.jsac.or.jp/analsci/.

\section{References}

1. Shiga Prefecture, Kankyohakusyo, 2006, 42.

2. H. Tatsumoto, T. Hattori, T. Furukawa, I. Ikushima, M. Kurihara, and I. Abe, Nippon Kagaku Kaishi, 1991, 852.

3. A. Imai, T. Fukushima, K. Matsushige, T. Inoue, and T. Ishibashi, Jpn. J. Limnol., 1998, 59, 53.

4. T. Hori, Y. Sugiyama, and M. Sugiyama, Jpn. J. Limnol., 1998, 59, 39.

5. Y. Sugiyama, M. Sugiyama, and T. Hori, Limnology, 2000, $1,171$.

6. Y. Sugiyama and T. Kumagai, Anal. Sci., 2001, 17, 77.

7. S. Aoki, Y. Fuse, and E. Yamada, Anal. Sci., 2004, 20, 159.

8. K. Nagai, S. Aoki, Y. Fuse, and E. Yamada, Bunseki Kagaku, 2005, 54, 923.

9. S. Aoki, S. Ohara, K. Kimura, H. Mizuguchi, Y. Fuse, and E. Yamada, Anal. Sci., 2008, 24, 389.

10. Shiga Pref. Inst. Pub. Hlth. \& Environ. Sci., "Data Compilation of Phytoplankton in Lake Biwa," 1984, 1985,
1986, 1991, 1995, 2000, and 2005

11. N. Kishimoto, Abstracts of the 70th Conference of the Japan Society of Limnology, 2005, 178.

12. E. Yamada, T. Ozaki, and M. Kimura, Anal. Sci., 1998, 14, 327.

13. A. Watanabe, K. Itoh, S. Arai, and S. Kuwatsuka, Soil. Sci. Plant Nutr., 1994, 40, 601.

14. S. Kuwatsuka, A. Watanabe, K. Itoh, and S. Arai, Soil. Sci. Plant Nutr., 1992, 38, 23.

15. K. Tanbo and T. Kamei, Journal of Japan Water Works Association, 1993, 62, 28.

16. T. Fukushima, A. Imai, K. Matsushige, T. Inoue, and H. Ozawa, J. Water Environ. Technol., 1997, 20, 397.

17. E. Yamada, K. Doi, K. Okano, and Y. Fuse, Anal. Sci., 2000, 16,125 .

18. S. Nagao, Y. Suzuki, Y. Nakaguchi, M. Seno, and K. Hiraki, Bunseki Kagaku, 1997, 46, 335.

19. P. G. Coble, S. A. Green, N. V. Blough, and R. B. Gagasian, Nature, 1990, 348, 432.

20. P. G. Coble, Mar. Chem., 1996, 51, 325.

21. N. Senesi, Anal. Chim. Acta, 1990, 232, 77.

22. M. Fukushima, S. Tanaka, K. Nakayasu, K. Sasaki, H. Nakamura, and K. Tatsumi, Anal. Sci., 1997, 13, 1011.

23. M. Fukushima, A. Kikuchi, K. Tatsumi, and F. Tanaka, Anal. Sci., 2006, 22, 239.

24. B. J. H. Mattews and A. C. Jones, Mar. Chem., 1996, 55, 317.

25. C. M. Sharples and L. B. Megown, Environ. Sci. Technol., 1999, 33, 3264.

26. M. Fukushima, K. Tatsumi, and S. Nagao, Environ. Sci. Technol., 2001, 35, 3683.

27. A. Baker, Environ. Sci. Technol., 2001, 35, 948.

28. J. A. Leenheer and P. Croue, Environ. Sci. Technol., 2003, $37,18$.

29. C. A. Stedmon, S. Markager, and R. Bro, Mar. Chem., 2003, 82, 239.

30. K. M. G. Mostofa, T. Yoshioka, E. Konohira, E. Tanoue, K. Hayakawa, and M. Takahashi, Limnology, 2005, 6, 101.

31. T. Fukushima, J. Park, A. Imai, and K. Matsushige, Aquatic Sci., 1996, 58, 139.

32. J. Buffle, P. Delamdoety, J. Zunstein, W. Haerdi, and Z. Schweitz, Hydrology, 1982, 44, 325.

33. S. Ichise, T. Wakabayashi, Y. Matsuoka, S. Yamanaka, N. Fujiwara, and K. Tanaka, Rep. Shiga Pref. Inst. Pub. Hlth. \& Environ. Sci., 1995, 30, 27.

34. I. Takahashi, K. Tazaki, T. Tajima, H. Kohno, and K. Takeshita, Journal of Japan Water Works Association, 2006, $75,15$. 